\title{
Slum Networking - A paradigm shift to transcend poverty with water, environmental sanitation and hidden resources.
}

\author{
H. Parikh* and P. Parikh** \\ * Principal, Himanshu Parikh Consulting Engineers, 2 Sukhshanti, 10/A Parnakunj, Near Ambawadi Circle, \\ Ahmedabad 380 006, India (E-mail: bhhp@youtele.com; hhp@dataone.in) \\ ** PhD Researcher, Newnham College, Department of Engineering, Cambridge University, Trumpington Street, \\ Cambridge CB2 1PZ, UK and senior consultant Arup International Ltd. (E-mail: priti_parikh@hotmail.com)
}

\begin{abstract}
This paper explores an alternative development paradigm which shifts from the present 'social paternalism' to the one which uses water and environmental sanitation infrastructure to alleviate poverty. As aid is neither adequate nor sustainable, it argues that aid dependence for infrastructure investment can be overcome by inherent resources within the developing world and the hereto unrecognised latent resources of the 'poor'. On the technical side, an innovative concept of Slum Networking is put forward to bridge the gap between the costs and affordability. It exploits the correlation between slums, natural riverine paths and infrastructure at macro level and technical innovations at micro level to improve performance and provide house-to-house integrated services at costs less than public latrines and handpumps. The paper is based both on actual work covering about a million people in India as well as research and data analysis of developed and undeveloped slum settlements.
\end{abstract}

Keywords

Poverty alleviation, water, environmental sanitation, latent resources, multiplier, Slum Networking

\section{INTRODUCTION}

\section{Scale of problem}

According to a UNHABITAT study, 924 million people, or $31.6 \%$ of the world's urban population, lived in slums in 2001 (UN-HABITAT, 2003). Planning Commission of India estimates that 26.1\% of India's population was living below the poverty line in 2000 the slum population in urban India in 2002 was 61 million (CSO, 2002). However, the United Nations website for the Millennium Development Goals Indicators has higher slum figures based on tenure criteria showing that 55.5\% of urban India lived in slums totalling 158 million. Going by the $\$ 1$ per day (PPP) definition, 43.3\% of India's population falls below the $\$ 1$ income mark (UN, n.d.a.).

More than a billion people worldwide have no access to an improved water source, and 2.5 billion do not have access to improved sanitation (WB, 2004). Studies show that there are inequities in service provisions across and within countries either in the form of the rich-poor or urban-rural divide (UNICEF/WHO 2004, WB 2004, UNDP 2006). The poor often consume fewer infrastructure services and pay higher prices. The price subsidies reach the rich consumers but not the poor who equally contribute to the economy in the form of market labour.

\section{Shortcomings of Millennium Development Goals}

The Millennium Development Goals developed by United Nations to address global poverty noted that a large proportion of the world's population is not covered by the most basic amenities. It is anticipated that there might be 2 billion people living in slums in the next 30 years (UN-HABITAT, 2003). Goal 7, looking at environmental sustainability, has three targets:

Target 9: Integrate the principles of sustainable development into country policies and programmes and reverse the loss of environmental resources. 
Target 10: Halve by 2015 the people without access to safe drinking-water and sanitation.

Target 11: By 2020 achieve significant improvement in the lives of 100 million slum dwellers.

The recent DFID Target Strategy Papers recognise infrastructure development as an essential prerequisite to achieving the Millennium Development Goals (DFID, 2002). The UNICEF/WHO (2004) mid-term progress report demonstrates how all the goals of the Millennium Development to alleviate poverty are directly or indirectly linked to improvements in water and sanitation.

However, the current trend to poverty alleviation entails a cocktail of interventions in health, education, governance with water and sanitation playing a subsidiary role and funding is invariably through aid assistance or soft loans. Studies (UNICEF/WHO 2004, UN 2007, HC 2007) show that the world is lagging behind a long way from meeting the Millennium Goals. For instance, the WHO/UNICEF (2004) monitoring report acknowledges that without a sharp acceleration in the rate of progress, the world will miss the sanitation target by half a billion people with the situation being most serious in South Asia, Sub-Saharan Africa, East Europe, Eurasia and Oceania. On the present trajectory the living conditions of the poor are unlikely to improve in the foreseeable future.

\section{SLUM NETWORKING}

\section{An alternative paradigm}

In a paradigm shift from 'social service' to 'business on hand', Slum Networking uses water and sanitation infrastructure correlated with nature to alleviate poverty; overcoming aid dependence with resources of the community and local partnerships. It does not accept that the constraints, both physical and financial, are insuperable and is underpinned by a fundamental belief that slums need not exist in India and this massive transformation can be achieved in a short time span (Parikh $\mathrm{H}$, 1995). The approach demonstrates three innovations new to the present development thinking:

- Of all the leverages available, water and environmental sanitation infrastructure can alleviate poverty cheaper and faster than any other interventions to dramatically improve incomes, community investments, health, literacy and other social indicators.

- The 'poor' have a latent resource potential yet to be tapped fully. We have seen that the water and environmental sanitation stimulates massive community investment in its own shelter and the 'poor' can, in conducive circumstances, mobilise huge resources. Thus, the community is not a 'beneficiary' but a capital partner committed to the development and its subsequent maintenance. Community investment is also an acid test of the efficacy of the solutions. As aid is not sustainable or adequate to meet the global needs, the challenge can only be met from the internal resources of nations through constructive partnerships. The business and banking partners replace aid and assist with implementation on a business model. The government's role is to establish a financial, administrative and legal structure to enable all actors to participate.

- The gap between the costs and resources can be bridged through technology and nature. There is a close correlation between water and sanitation infrastructure, natural drainage topography of settlements and the location of poor areas. This can be exploited to improve the environment and provide high quality, gravity based, house-to-house water, sanitation, storm drainage, roads and landscaping at costs lower than the conventional 'slum' solutions such as public standposts and community latrines.

\section{The Macro Level}

The idea of Slum Networking first germinated in 1987, when working in the slums of Indore, their 
proximity to streams and rivers was noticed. Studies of other cities in India and abroad showed the same relationship. Could this correlation with nature provide economic, gravity based water and drainage networks? If rivers do not need pumping stations, why should drainage? If slum services are interconnected along these riverine paths, the main city can also gain cost effective networks in the process. Thus slums, instead of being resource-draining liabilities, become opportunities of a quantum change in the infrastructure levels and environmental quality of the city. This co-ordinated process of treating the city slums as an urban net can replace the overlapping and often conflicting infrastructure developments which are currently being undertaken in a piecemeal way by a

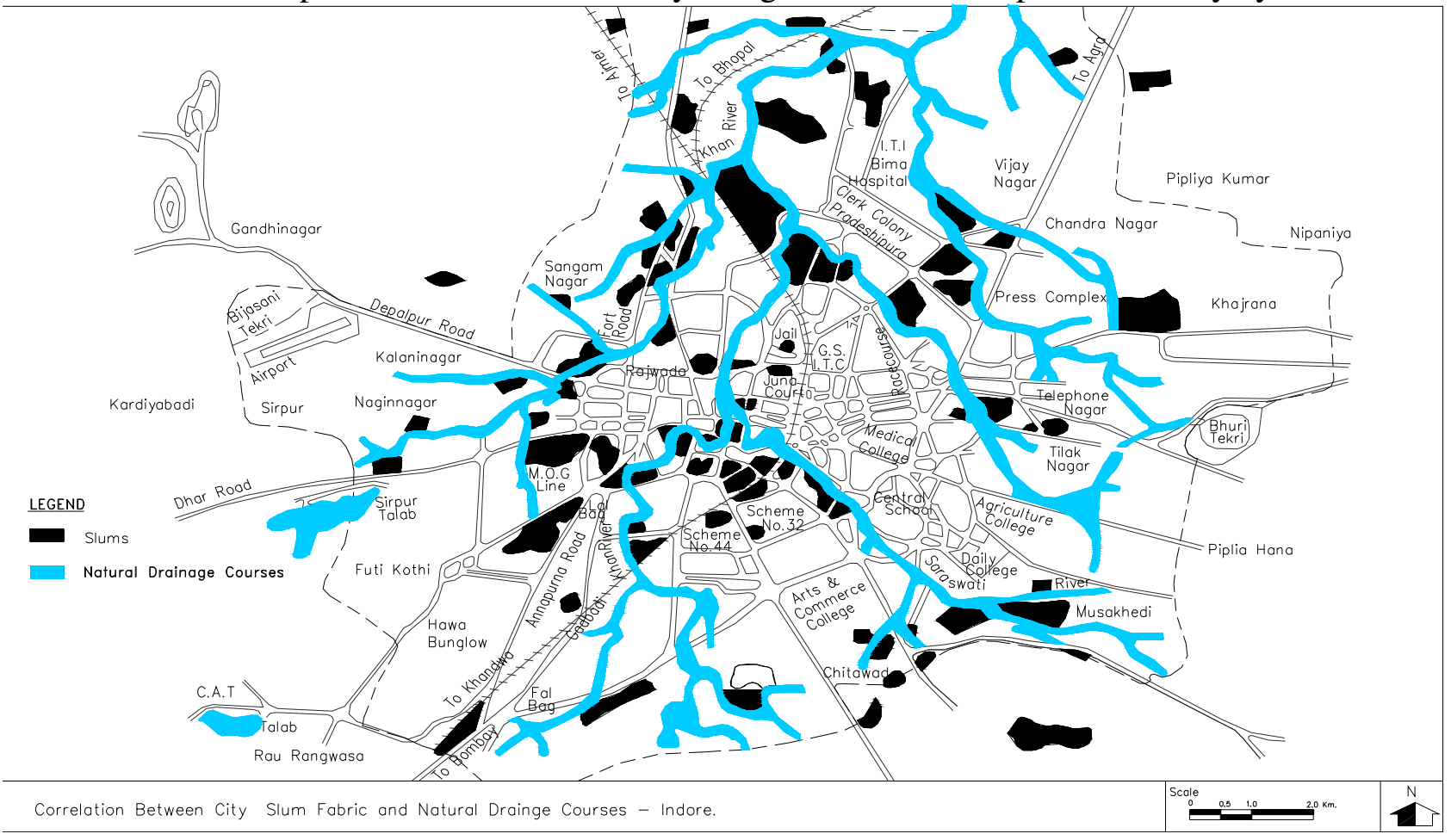

multitude of agencies (Sandhu, 1998).

Figure 1: Correlation between the city slum fabric and natural drainage paths
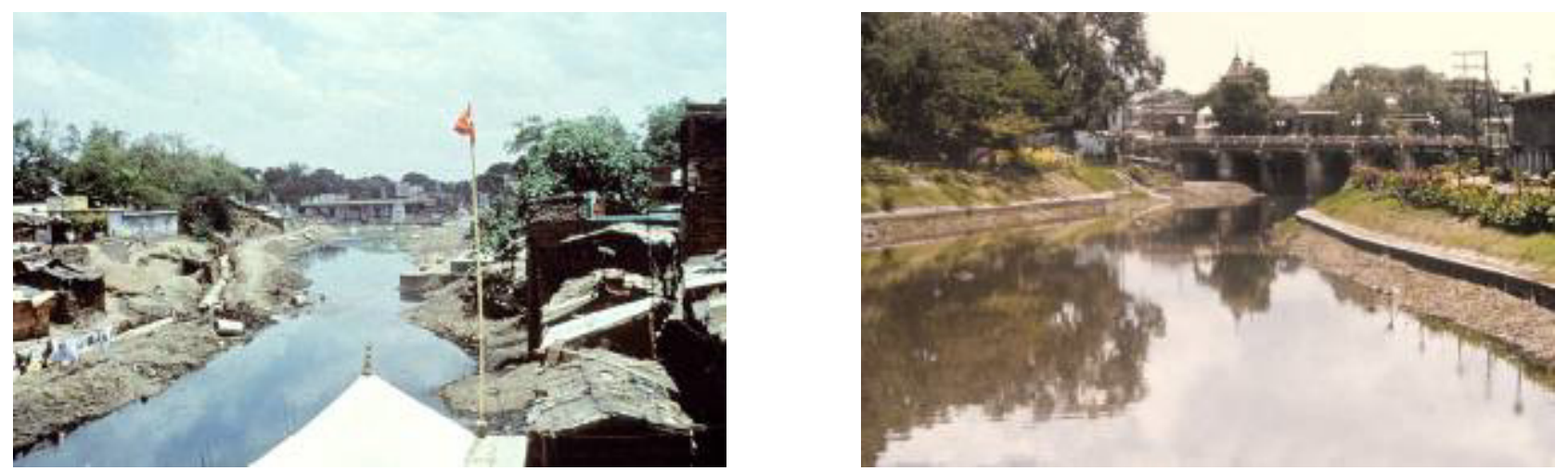

Figure 2: Indore river before and after Slum Networking.

Over a period of six years, the slum matrix of Indore city, covering 450,000 persons, was upgraded with environmental and sanitation improvements. The slums were integrated into the city fabric through the improved road and sewerage networks (Diacon, 1997).

An arguable weakness of the Indore project is that it was funded from a UK government grant and the community did not have a role in project formulation, implementation and maintenance. Whilst 
the Development Authority executed the programme, the subsequent maintenance was handed over to the Municipal Corporation (local government) without the commensurate resource mechanism. The result was that the communities failed to take ownership of the underground sewerage, storm drainage, landscaping, earth management, solid waste and maintenance.

The next step, therefore, was to move towards greater self sufficiency and greater community control. A pilot project was implemented in Ramdevnagar slum in Baroda city, in which the community, Municipal Corporation and UNICEF shared the project costs. Baroda Citizen's Council (BCC) an NGO set up by local federation of industries successfully implemented the project. The outcomes of the project have been documented by UNICEF. According to UNICEF (1999, page 6):

Following Indore, Bhopal and Baroda, a project implemented in Sanjaynagar slum in Ahmedabad took Slum Networking a step further by replacing external aid with contributions from business (Arvind Mills) to match the resources put in by the slum dwellers and the Municipal Corporation. The provision of basic services like water, drainage, street lights, toilets and internal roads was made possible by making legal amendments in Section $82 \mathrm{C}$ of the Bombay Provincial Municipal Corporation Act, 1958 which would permit Ahmedabad Municipal Corporation (AMC) to provide basic services in the slums located on reserved and private lands (Acharya and Parikh, 2002).

\section{The Micro Level}

At the micro-level Slum Networking provides holistic physical improvements, namely, roads, individual water supply and sewerage, storm drainage, earthworks, soft landscaping, power and streetlighting. All the components of infrastructure are bundled for economy and integrated from slum to city with respect to topography. Innovations such as holistic computer modelling, roads as storm channels, earth management, miniature appurtenances, constructive landscaping, flushing of sewers with rain and self ventilated manholes improve performance and cut costs (Parikh P, 2005). 

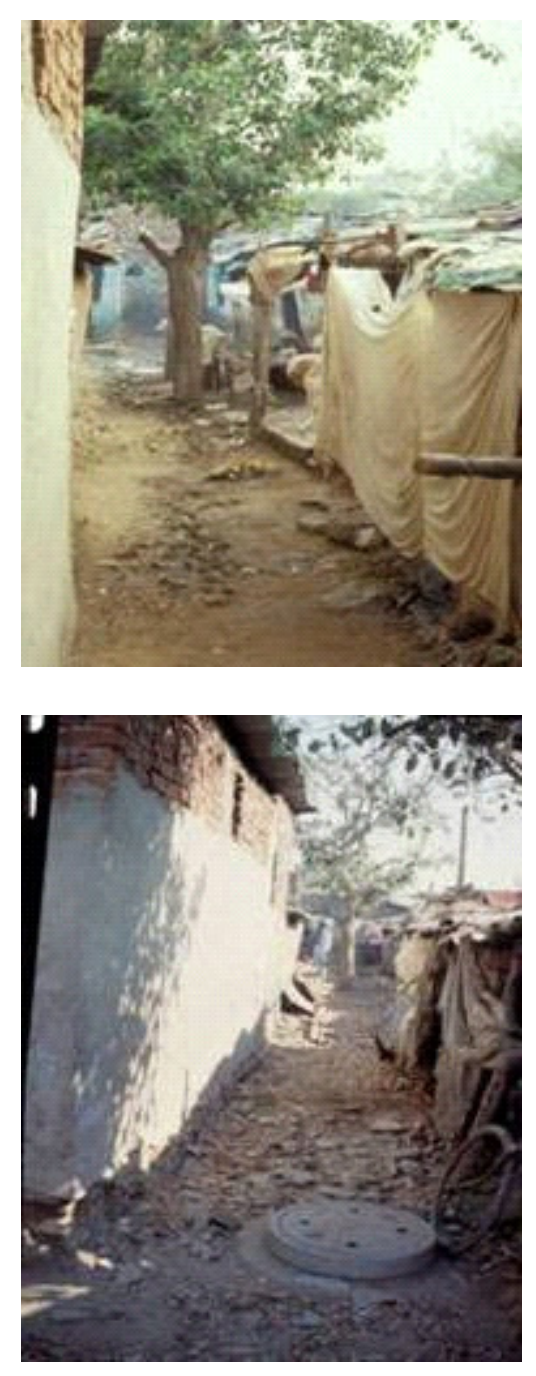


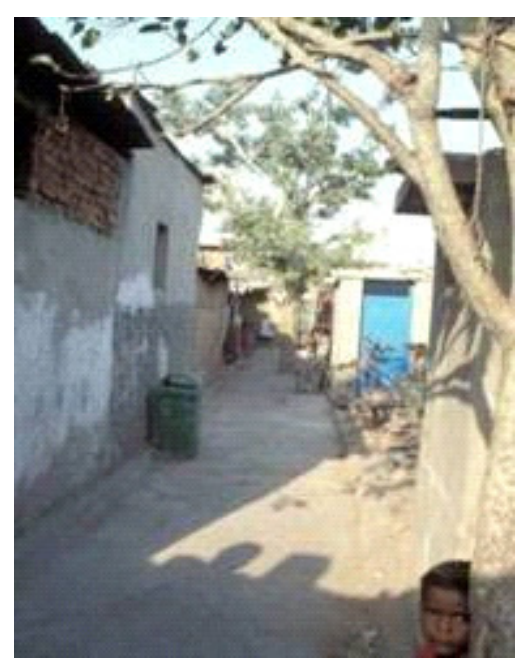

Figure 3: Sanjaynagar before, during and after development. Note the change in housing stock.

\section{Roads and topography management}

Roads are the main corridors of all other services and, if planned well to the natural topography, lead to efficient and economic infrastructure as a whole. The roads are placed in cut below the surrounding ground and engineered to slope continuously down, so that storm water and sewage flow by gravity without pumping and manholes remain shallow and cheap. The design challenge is to provide minimal roads, with least disruptions to existing settlement, and yet giving maximum access. The design optimization was in trading off between the road placed predominantly in cut, balancing cut and fill, continuously sloping the road down and maintaining its levels just below the house plinths (to stop house flooding). The layers of road pavement were optimized to use maximum thicknesses of the cheaper local materials (such as murum) for the base and sub-base, whereas the more expensive materials were limited to the thinner surfacing layers.

Figure 4: Principles of earth management in road design.

\section{Storm water}

The absence of storm drainage in Indian cities has devastating impact in monsoons, especially when coupled with other infrastructure deficiencies. Dirt roads become treacherously muddy. The logged areas, contaminated by overspill from open sewers, become breeding grounds for mosquitoes and flies. Outbreaks of epidemics are common during monsoons. Conventional piped storm drainage is unaffordable in view of the huge monsoon storm loads. Open masonry storm drains are equally expensive, difficult to maintain and unsanitary as they get clogged by solid waste and excreta.

To meet the challenge, an innovative concept of road section combined with piped drains was developed. Roads laid as channels, in excavation and continuously sloping down, act as primary water carriers, supplemented by piped drains only when the road edges flood to a tolerable limit of $50 \mathrm{~mm}$. Thus, both the pipe lengths and their diameters reduce substantially. The system has all the advantages of a fully piped system at a tiny fraction of the cost. Studies by Kolsky of Indore slums have validated this concept (Kolsky, 1998)

Figure 5: Roads complementing storm drainage. 

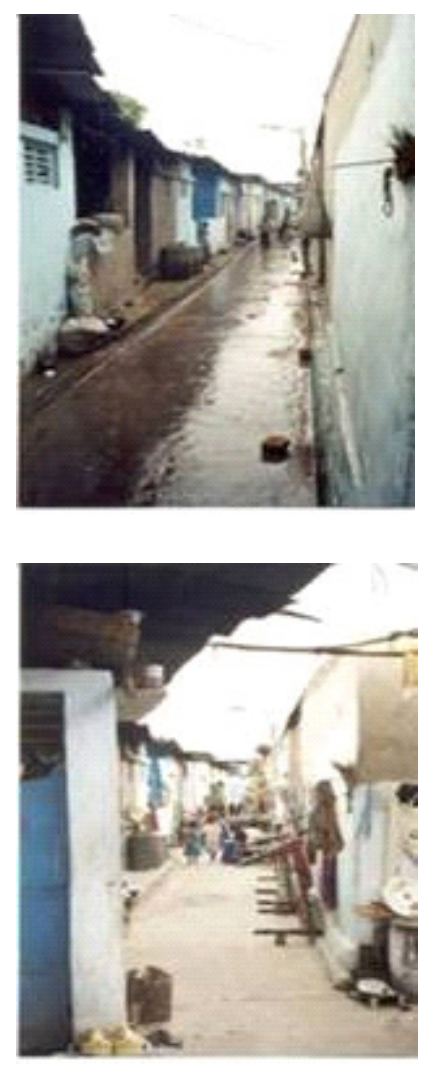

The complex calculations of open channel flow on roads in combination with the closed flow of the piped storm drainage are incorporated in the computer model so that the two can be designed interactively for better performance and economy. Using these measures, the storm pipes below Sanjaynagar roads were totally eliminated.

Figure 6: Road on a dry and a wet day.

\section{Water supply}

Before development, women and girls had to queue long hours for water at the public taps in surrounding societies at a loss of time and dignity. Thus, there was a strong demand for individual connections.

Looped networks were preferred to branches for better pressure balance across the system and smaller pipes are required to achieve the same terminal pressures. The principal design trade offs are between the network layout and pipe diameters (cost) against the terminal pressures across the system, both evenly balanced and with reasonable head (performance).

PVC pipes were laid shallow for economy but protected from impact damage by the concrete pavement above. Evaluation of Sanjaynagar ten years after implementation has shown that this has turned out both cheaper and more durable than using stronger but dearer cast iron pipes as conventionally preferred.

\section{Sewerage}

Underground protected sewerage is sparse in most cities and villages of India. Sewage, sullage and storm water collect on streets or in open drains, which are usually blocked, creating serious health and safety risks. In slums, individual toilets are very few and most people defecate in the open as 
they have no sanitation facilities, private or public. There is a huge demand, especially from women, for better sanitation facilities even if that entails contributions from them. A comparison of individual versus community facilities show that the former may possibly be an effective solution in terms of not just capital costs but also in the subsequent running, maintenance and failure costs. For example, the total cost in Sanjaynagar for the total infrastructure and individual services was Rs. 13,000/family (\$325) in 1995 (including household toilet cost) whereas the cost per family for a slum sanitation project in Mumbai in the same year was Rs. 11,000 (\$275) just for public latrines without any other infrastructure, considering the number of dysfunctional public toilets in Mumbai at about $45 \%$
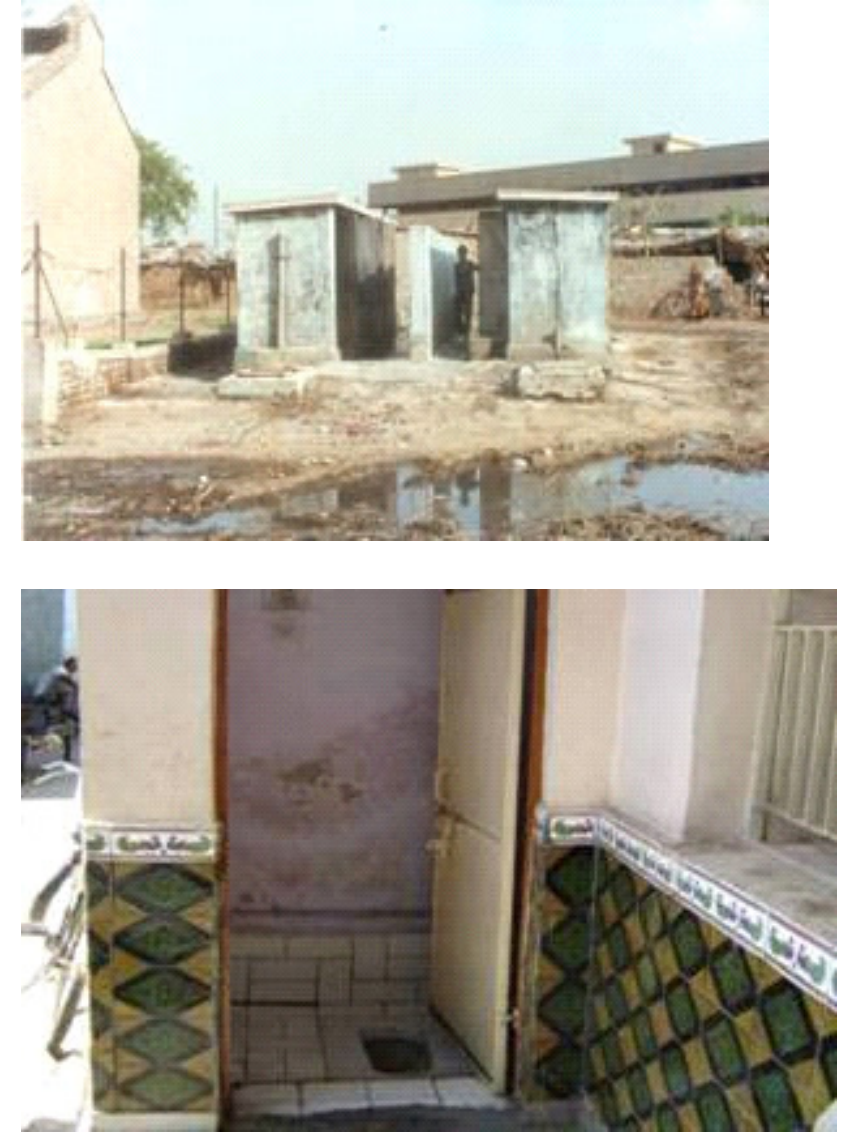

(MCGB, 1995) compared to almost none for Sanjaynagar settlement.

Figure 7: Sanjaynagar public toilet before development and individual toilets afterwards.

'Shallow sewers' have been successfully used in Slum Networking projects in India. To attain flushing velocities in the initial runs, star pattern collection is used to accumulate flows and the runs are kept flat and shallow with 'tractive force' design. This requires lower velocities to keep solids just moving as against the normal velocities to keep them in suspension. As an added insurance, sewer lines are flushed with storm overflows. The sewerage is laid along road centres and the manhole covers provided with holes to let in storm overflows, which reach the crown levels once or twice each year when the rain intensities exceed that of the design return period.

The breathing holes in manhole covers help to ventilate the system. The expensive appurtenances such as flushing tanks, vent shafts and pumping stations are eliminated. Small intercepting traps replace the house connection manholes, saving about $25 \%$ on the sewerage cost. The traps are placed at the doorsteps so that the misuse at entry points, which accounts for most blockages, is controlled directly by individual families who assume responsibility instead of the local authority. 


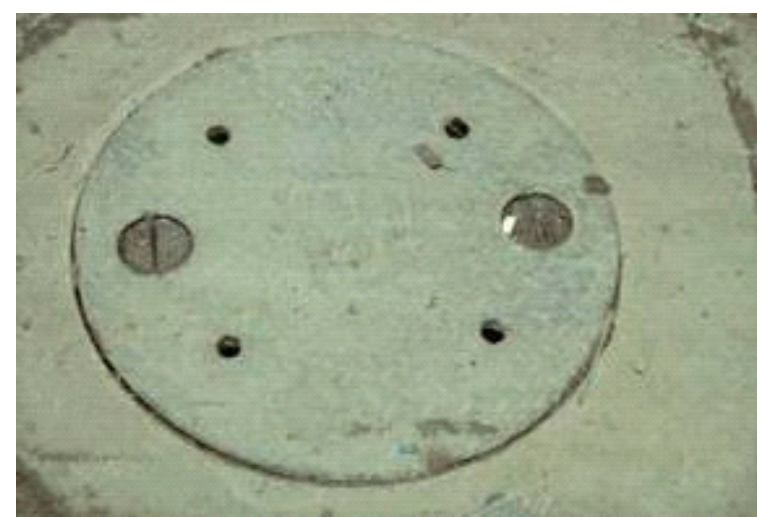

Figure 8: Ventilated manhole cover
Figure 9: Miniature gulley trap replacing manhole

\section{Solid waste management}

Solid waste management is a vital urban service from the point of view of environment and hygiene and yet often neglected. The problem cannot be solved by mere provision of dustbins.

Open drains are avoided in the design as they become dumping grounds for solid waste. The collection, transportation and disposal of solid waste outside the slums is managed by the local authority and by the community within the settlement. Rag pickers are integrated into the process to generate incomes from recycling and at the same time provide training for safe handling of waste.

\section{Landscaping}

Thoughtful planting can improve the microenvironment. Trees shade the streets in summer and at the same time reduce the dust in the air. Decorative trees and flowering plants add to the beauty. The vegetable, herb and fruit plants supplement the daily needs of the families.

Landscaping is also used as an engineering tool. By sinking the roads below the adjacent land, the excavated material is used to fill up the low-lying areas and regrade the slopes. This helps to drain the water towards the roads and the storm systems instead of ponding. Subsequent grassing binds the surfaces at a fractional cost of hard paving and checks silt erosion. Grasses absorb water and reduce its speed of flow, thus recharging the ground and reducing the peaks in the storm systems.

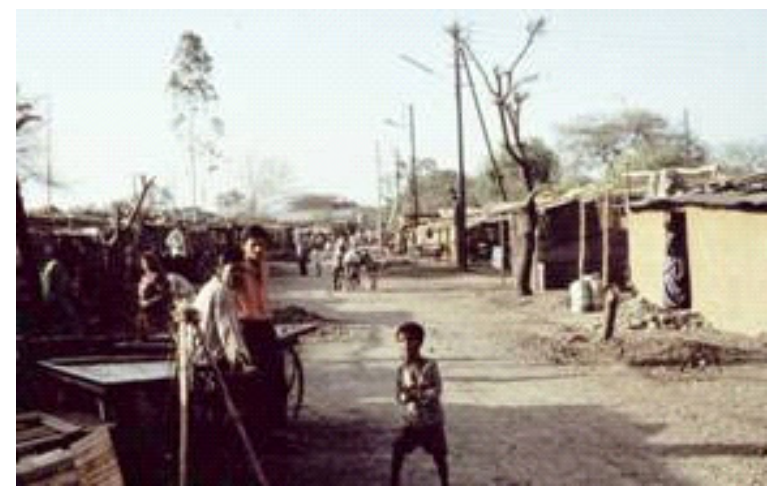




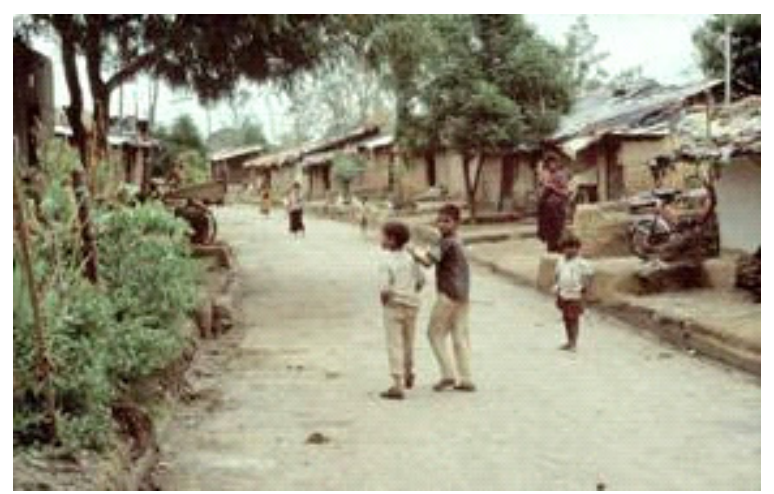

Figure 10: Impact of landscaping on Indore slum before and after development.

\section{Power and streetlighting}

Overhead cables pose a serious safety risk in slums, where pilferage from the poles is common, sometimes resulting in injuries and deaths during illegal tapping. Similarly, in Uttarayan, the kite festival, the kites get entangled with overhead lines and cause injuries and power disruptions. In Sanjaynagar, underground cables were used for power and streetlights, although this is not a conventional practice. The industry partner Arvind Mills helped with the negotiations between the community and the electricity company and co-ordinated the works so that the lines were installed before the road works to avoid subsequent re-digging (Tripathi, D., 1998).

Apart from improved visibility, streetlighting greatly increased the sense of safety and security of the community. The huge impact of electricity at home is discussed in the subsequent sections.

\section{DATABASE AND ANALYSIS}

This paper is based on the observations in the slums of four Indian cities where a million people have directly benefited from the concept, together with pilot research undertaken in2005 in Sanjaynagar slum, Ahmedabad, where holistic physical infrastructure under the Slum Networking Project was implemented in 1997. The special features of this case study are the involvement of the corporate sector, provision of tenure rights and community ownership. For comparative evaluation, second case study was an undeveloped slum located in Khokhra ward of the city, the primary difference between the two cases being the provision of physical infrastructure. In 2006 and 2007, the research was expanded to 500 households in five slums of India, and 200 households in two settlements in South Africa, both serviced and non-serviced, to validate the findings on a larger scale and across geographical and cultural range. (Parikh P, 2005 and 2008)

\section{IMPACT ON HEALTH}

\section{Medical expenses}




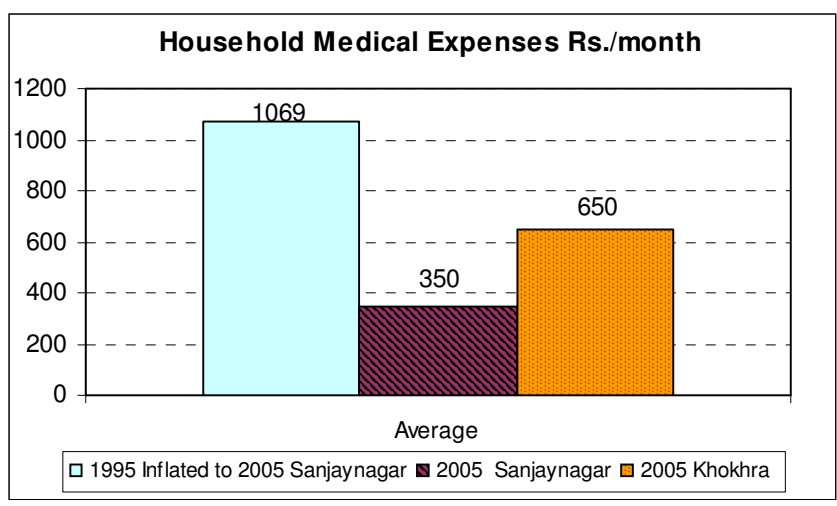

The comparison of average household monthly medical expenses shows marked differences in medical expenses between pre and post project Sanjaynagar. The monthly medical expenses for Sanjaynagar have reduced to almost one- third of the pre project. Similarly the current medical expenses in undeveloped Khokhra are double those in Sanjaynagar. The reduction in medical expenses means that the community has greater disposal resources and savings.

Figure 11: Household medical expenses

\section{Work days lost to illness}

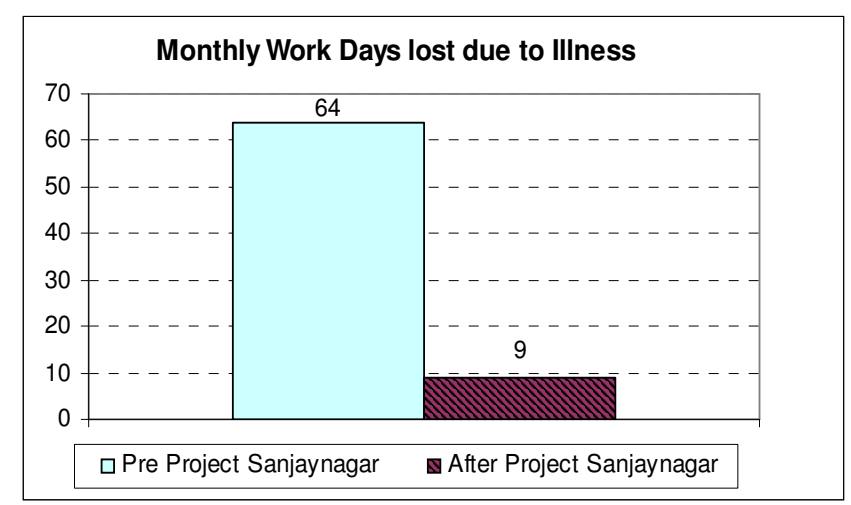

The comparison between pre and post project scenario in Sanjaynagar shows the number of work days lost to illness reducing significantly. Although the results could not be compared with Khokhra due to statistical incompatibility of unequal responses, the residents of Khokhra did complain of heavy loss of work days due to time spent in hospitals when they or family members are ill. The reduction in lost work days means increased incomes and more time for other meaningful activities like education.

Figure 12: Monthly work days lost to illness

\section{Infant mortality}



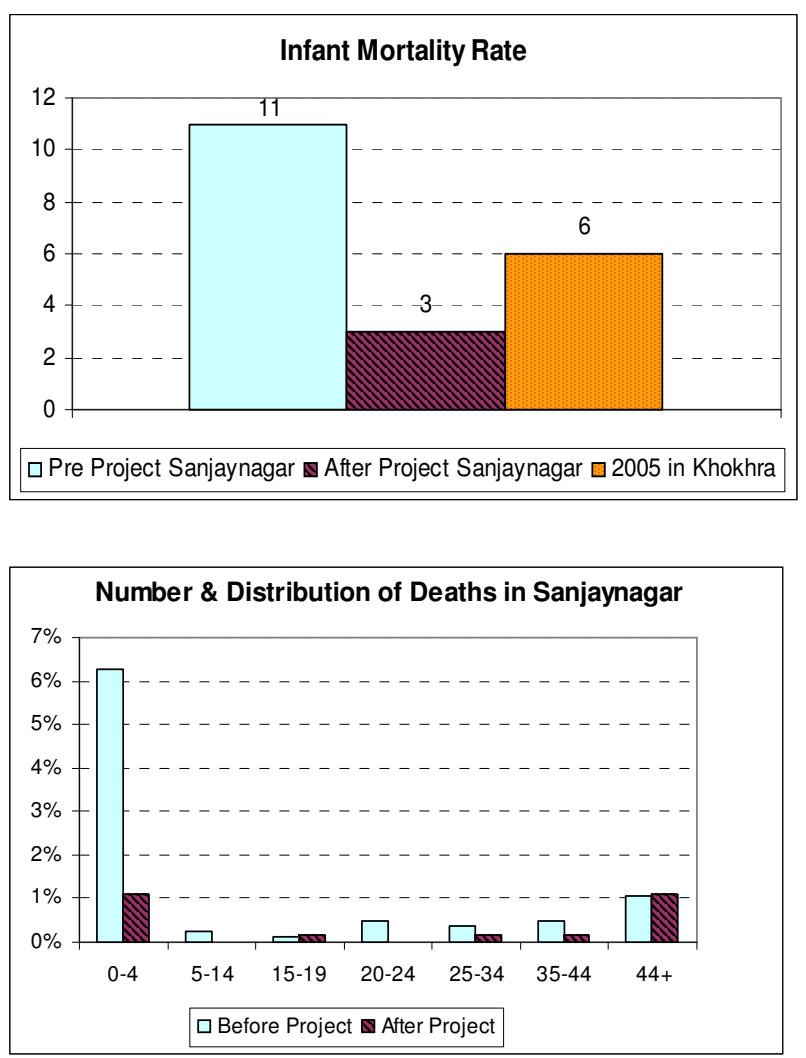

Children are particularly vulnerable to diseases like diarrhoea and malaria. Owing to reduced immunity any major or prolonged illness can result in death. The comparison between pre-project Sanjaynagar, post project Sanjaynagar and Khokhra shows infant mortality rate reduced to a third in Sanjaynagar post project implementation and also less than in the control Khokhra slum. The result matches with secondary studies for Sanjaynagar (SHARDA Trust and SAATH, 1999) for \% deaths across various age groups. The most dramatic reduction is observed in the 0-4 age group. Environmental sanitation appears to have brought about changes which would otherwise be very difficult to achieve even with the most intense care programmes.

Figure 13: Household medical expenses.

Figure 14: Reduction in under 4 deaths.

\section{Reasons for health improvements}

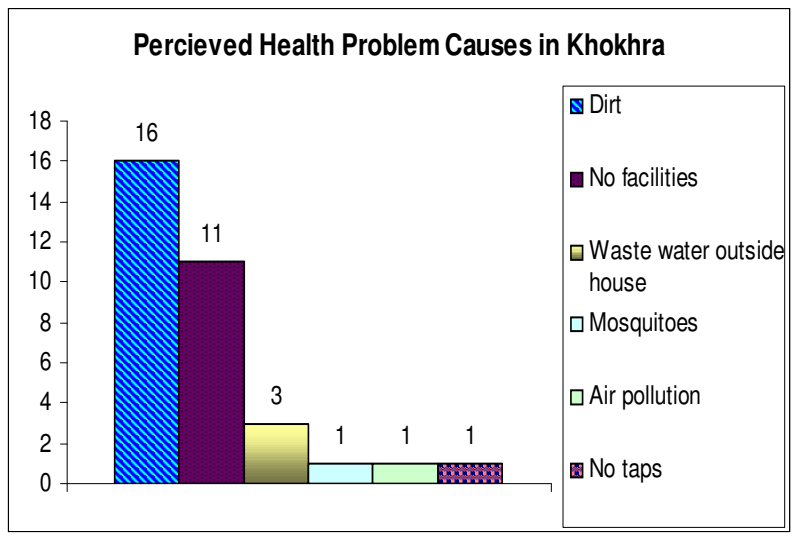

There are clearly health improvements in Sanjaynagar after development, with results better than the current Khokhra situation. Health interventions are ruled out for this improvement as they were neither substantial nor durable. The health clinic established during the project did not survive for long. For example, figures for Sanjaynagar show that immunisation drive during the project was not particularly effective (SHARDA Trust and SAATH, 1999). 100\% of the households surveyed in 
Sanjaynagar attributed health improvements to the provision of infrastructure. The Khokhra residents reported a high proportion of illnesses of recurring nature in their settlement. Dirty environment was perceived to be the main reason for the health problems. The next one was lack of facilities and then waste water outside house, mosquitoes, air pollution and no taps. All the causes related to infrastructure deficiencies of unpaved dirt roads, open drains and water logging.

\begin{tabular}{|l|r|l|}
\hline No. of & \multicolumn{1}{|c|}{ \% of } & \\
\hline & Before & After \\
\hline 0 & $0.78 \%$ & $13.86 \%$ \\
\hline 1 & $17.19 \%$ & $2.97 \%$ \\
\hline 2 & $12.50 \%$ & $3.96 \%$ \\
\hline 3 & $17.97 \%$ & $14.85 \%$ \\
\hline 4 & $20.31 \%$ & $19.80 \%$ \\
\hline & $31.25 \%$ & $44.55 \%$ \\
\hline Total & $100.00 \%$ & 100.00 \\
\hline
\end{tabular}

Figure 15: Immunisation in Sanjaynagar

Figure 16: Causes of health problems, Khokhra

\section{Qualitative perceptions on health}

During the group discussions and household interviews many other interesting observations were recorded. They are presented in the form of quotes as it is difficult to measure or quantify some of the benefits. For instance a lot of women in Sanjaynagar have highlighted that they no longer have to carry buckets of water which, apart from saving time and labour, has reduced their back problems. Other quotes:

"Water and drainage is a necessity for not only a king but also a pauper." Group Discussion, Sanjaynagar, 2005

\section{IMPACT ON EDUCATION}

The impact of education has been estimated both from attendance and the quality of education, based on the household interviews in Sanjaynagar and Khokhra. Information has also been drawn from community surveys (Sneh Prayas, 2004) which look at the educational background of all children in Sanjaynagar.

\section{School attendance}




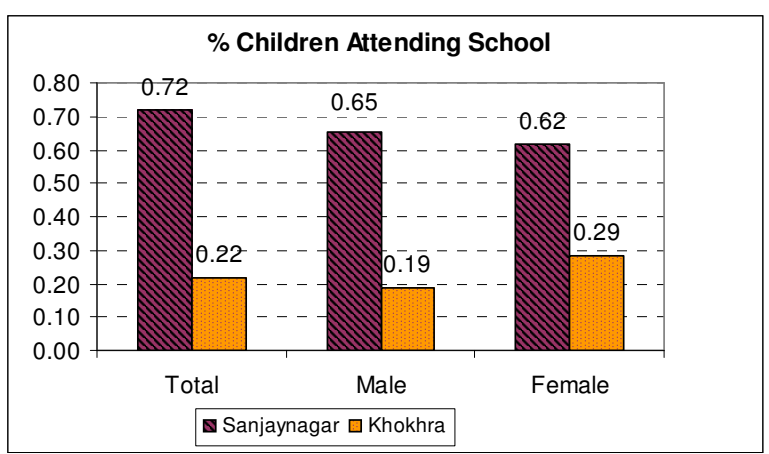

The $\%$ attendance is a ratio of number of children between the ages of 6 to 18 attending school divided by the total number children in that age group. On all counts post project Sanjaynagar shows a higher \% attendance compared to Khokhra. The Sanjaynagar figures also reflect the national trend of higher attendance rates of the male child, though it is worth noting that the percentage of female attendance has significantly increased post project.

Figure 17: \% children attending school

\section{Quality of Education}

In India municipal schools are run by the government. They do not charge fees to reach the children in the lower income strata. Private schools in India cater to middle and high income groups, though they are not normally as exclusive as the in the west. The group discussions and household interview showed that in Sanjaynagar private schooling was perceived as superior.

In Khokhra not a single child from the interviewed households went to a private school. A comparison of Sanjaynagar settlement showed an increase in the number of children, both boys and girls, attending private school post development. In order to send their children to private schools the families had to incur an average expense of Rupees 3872 per year for the fees, books, uniforms and transport. The average annual expense on education is equivalent to $40 \%$ to $75 \%$ of monthly incomes. In contrast the residents of Khokhra have not invested money for their children's education. It is not just the expense but the change in perception about education and the zeal to strive for high quality education which is more noticeable. The necessity of education is now entrenched in the mindset of Sanjaynagar residents whilst those in Khokhra feel that education is irrelevant as their children will work as labourers when they grow up.

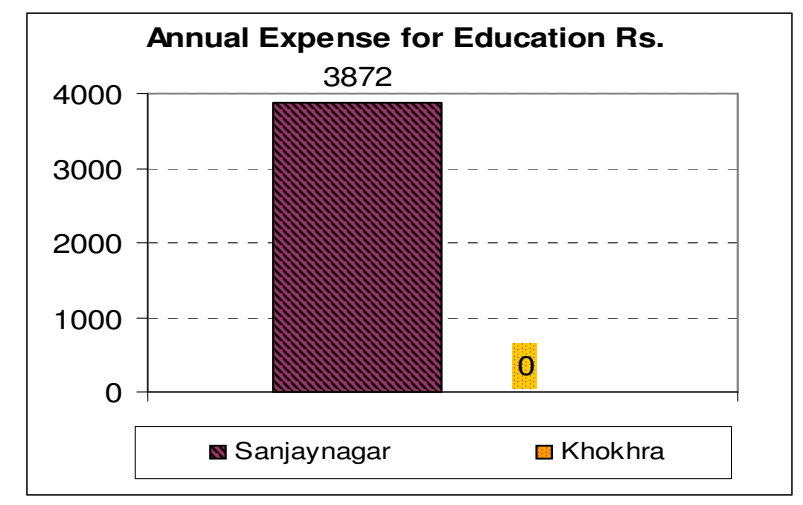




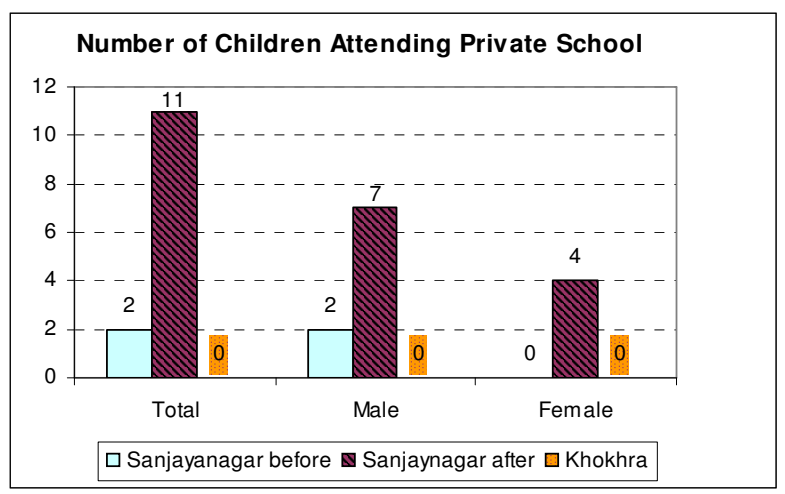

Figure 19: Annual expense on education

\section{Impact of electricity and television on education}

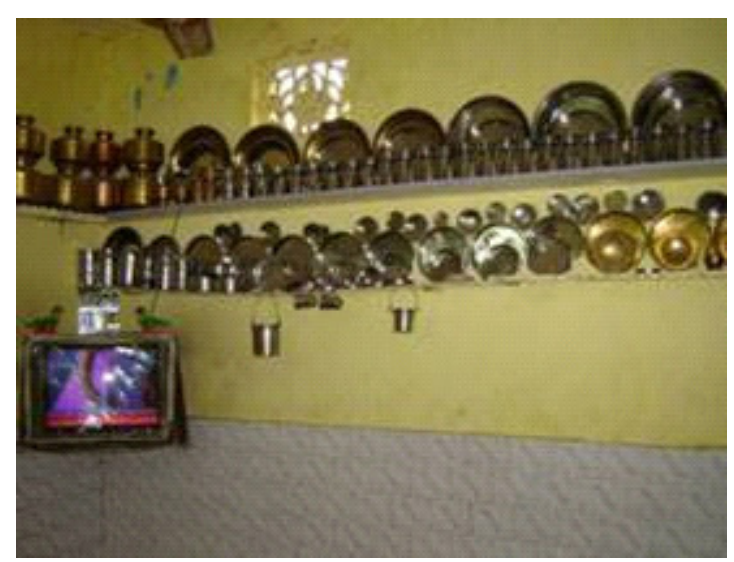

With electricity, people now have fans and lights to sit and read in the house during day and night. In Sanjaynagar people's lives have been transformed by television. Outside the classroom, this is an important medium of education. Out of 20 houses interviewed 17 families now have televisions against the earlier 3. 8 out of 20 houses in Sanjaynagar reported an increase of the age of marriage from 10-16 years to 18-20 years, respondents citing greater awareness due to television and education as a cause. The quotes below give some qualitative changes in lifestyle:

Figure 20: Television 


\section{Reasons for improvement in education}

Previous sections show a change in education both in terms of the numbers and the perceived value of education. The crucial question is the cause of this change. The main intervention in Sanjaynagar during this time was the provision of physical infrastructure/facilities. SAATH started a Balwadi (child education centre) but the centre was closed recently.

All the respondents in Sanjaynagar cited the infrastructure facilities to be the main cause of improvement in education. Similarly when the counter question was posed to the residents of Khokhra all the respondents highlighted that the lack of facilities as a reason for the problems with education. These perceptions strongly support the linkage between facilities and education.

"The time saved on water collection and disposal is used by children for schooling and by women for sending children to school, cleanliness and educating children." Group Discussions, 2005

\section{Qualitative perceptions on education}

"Education is the foundation of life and can help us immensely. People think that computers will also come one day." Group Discussions, 2005

"Municipal schools do not teach well. Children in private schools know ABCD and English from class 1 but children in municipal schools cannot even write their names in class 7. So we prefer to send our children to private school even though the fees are high." Group Discussions, 2005

"Children go to school now. Previously there was no time to send children to school. If the women go out of their houses to fetch water who will get the children ready to go to school?" Group Discussions, 2005

IMPACT ON INCOMES AND INVESTMENT

\section{Expendable incomes}

In Sanjaynagar an impression of increased spending was clear during the field work, as seen from lifestyle changes, investments in education, shelter upgradation and other spending. However, the problem in comparing directly reported incomes with secondary data is that the community on the whole is suspicious about income surveys. They under report their incomes and do not include informal cash transactions and subsidiary seasonal and irregular incomes, whereas secondary sources and cross checking with neighbours gives a different picture. It was thus decided to derive income from the quantifiable expenditures. Comparisons were made between the reported expenditures for pre and post Sanjaynagar scenario and Khokhra and the estimated current monthly spending for Sanjaynagar - i.e. expendable income.

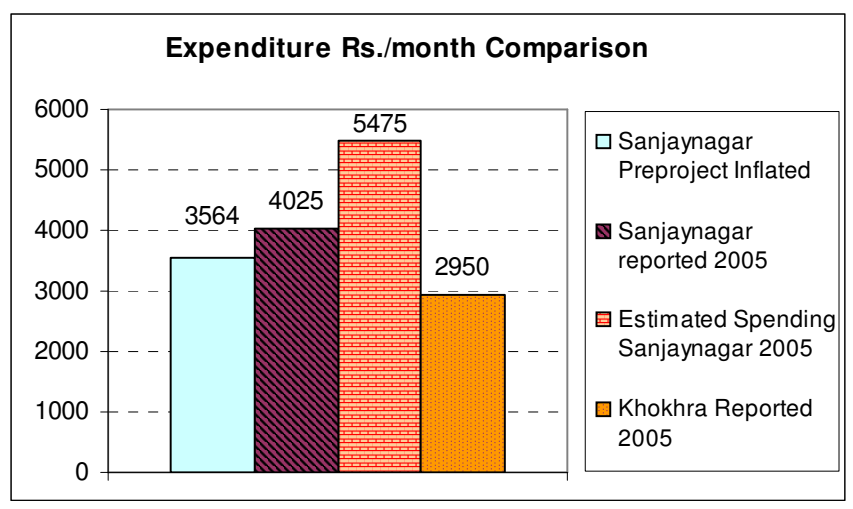

The current monthly spending was estimated from medical expenses, education costs, bills, electricity charges, cable TV costs and investments in vehicles and housing. Food, grocery and 
clothes expenditure was estimated from the consumption patterns and the number of members in a family. Expenditure patterns showed very clearly that disposable incomes in Sanjaynagar have almost increased by $50 \%$ in real terms post project and are almost double that of Khokhra. This is a remarkable increase.

Figure 21: Expendable income comparisons

\section{Reasons for Higher Expendable Incomes}

The expenditure pattern demonstrates almost a doubling of disposal incomes comparing post project Sanjaynagar with undeveloped Khokhra. The reasons for this increase cannot be absolutely established by simple surveys and statistical analysis. As the only major intervention in Sanjaynagar was in the physical facilities, and also as corroborated in group discussions, infrastructure provisions appear to be the principal catalyst of change.

"Income has increased and so have expenses. But people still feel happy as they have added facilities now and a different life style." Group Discussions, 2005

"Time saving for water collection and disposal also leads to income generation." Group Discussions, 2005

"There is a better chance to find work if we live in serviced houses as we will spend less time on water collection. Also it would be safer for women to work until late and come back in the night if the streets are paved and well lit." Group Discussions, 2006, Imizamo Yethu, South Africa

\section{Community willingness and ranking of investment priorities}

Prior to development all communities gave unequivocal top priority to investments in water and sanitation infrastructure in preference to housing, health, education and employment. This is reinforced by the reversal in priorities from infrastructure to other segments once the physical development work was done in Sanjaynagar.
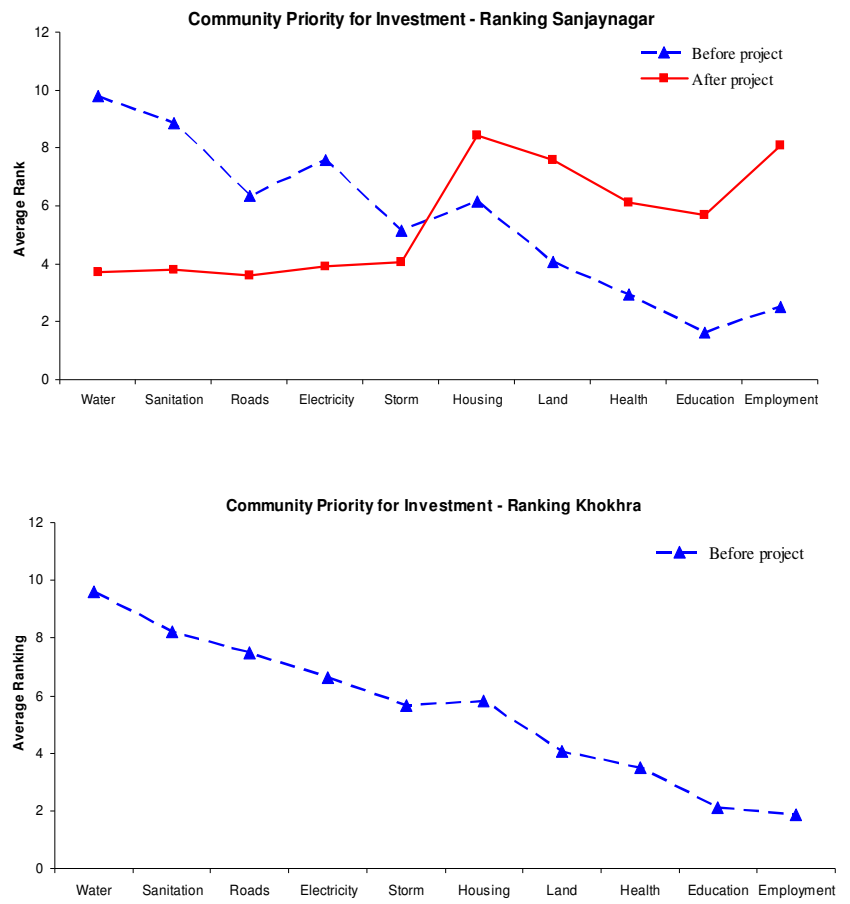

This is in contrast to the perceptions in most development agencies that, whilst water and sanitation 
is important, priority investments should be in sectors such as health, education and governance. Whilst professing community participation and grass roots planning, it is ironic that the developmental scene is discordant with people's wishes (Parikh P, 2008).

Figure 22: Change in investment priorities before and after development

\section{The investment multiplier}

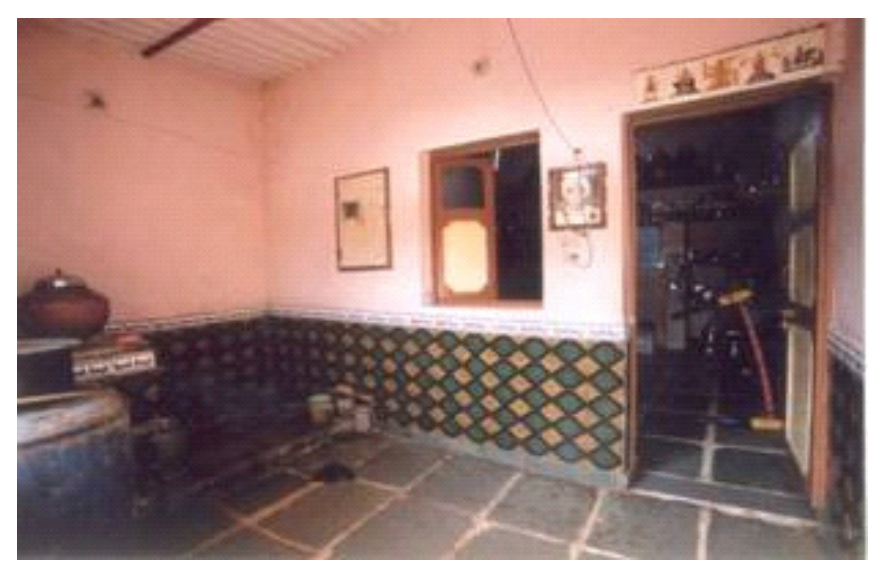

The investments in housing by the community were recorded in the study. However, as these were carried out in stages with the possibility of under or over reporting, the stated investments were cross checked and brought on par to present prices on the basis of built up area, type of construction and the prevailing construction costs.

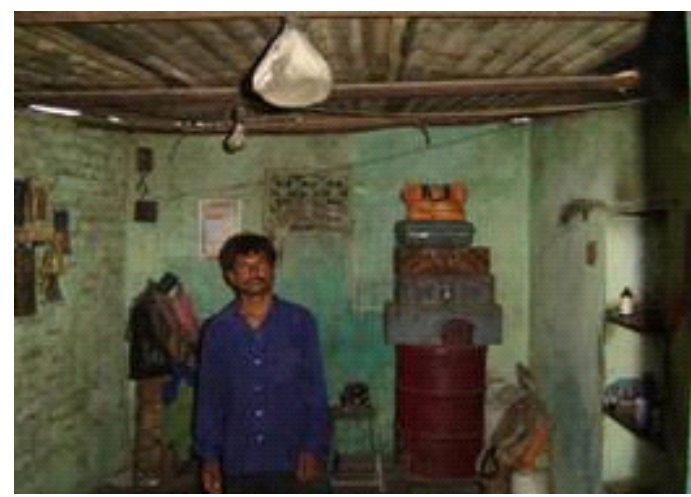

Figure 23: The housing stock - before and after development

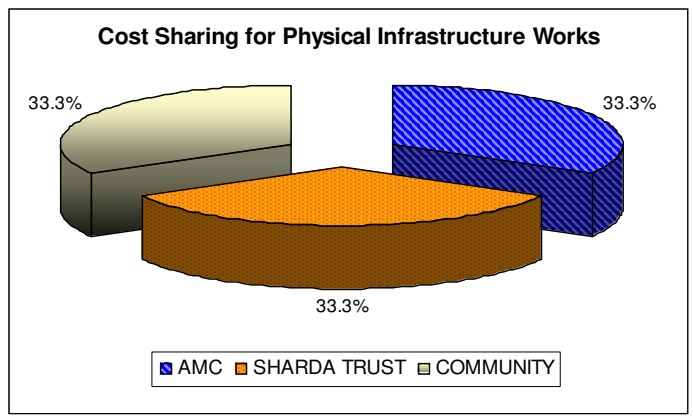




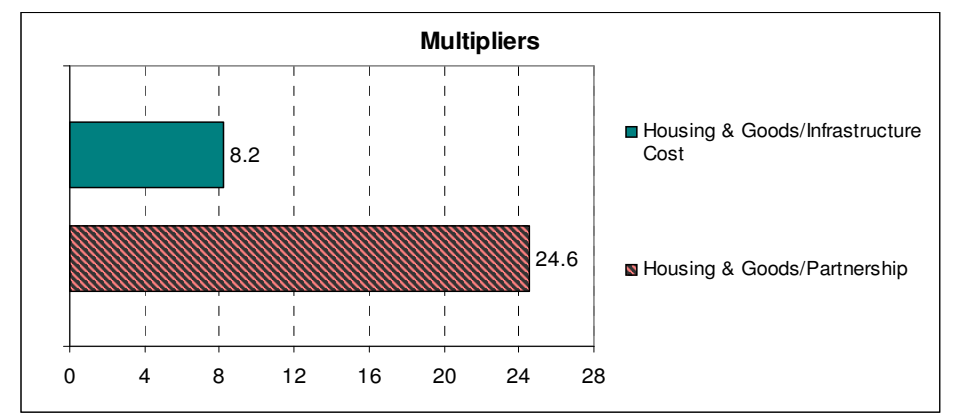

In addition, there were substantial investments in goods like televisions, phones, refrigerators and vehicles. The figure below shows that investment in housing and goods in Sanjaynagar was 8.2 times the initial investment in physical infrastructure. If the infrastructure costs are shared on partnership basis, the government investment drops to a third and the multiplier on the state investment increases to a massive 24.6 times! This is a crucial point for formulating habitat projects in countries, where government resources are scarce and the problems of poverty widespread. Huge public investments have gone into housing, whereas the same end results can be achieved at far lesser costs through catalytic investments in infrastructure and financial partnerships.

Figure 24: The investment multiplier after services

The reasons for investments in housing

Figure25: Partnership in Sanjaynagar
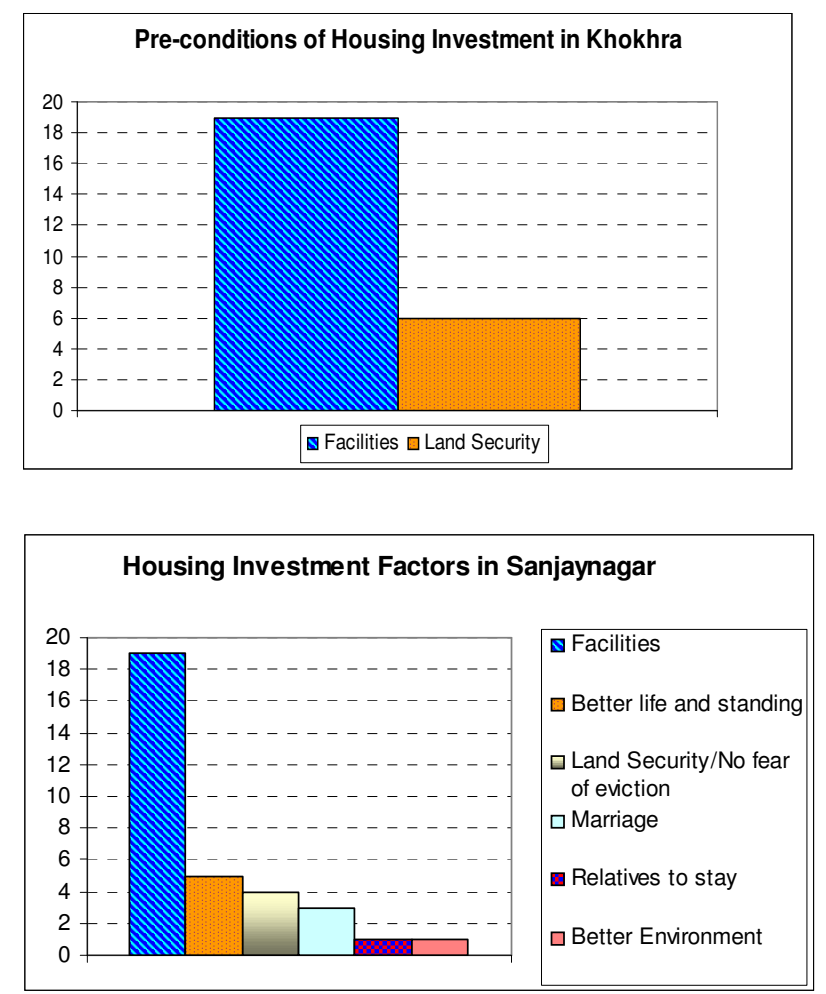

It is established that the community has made huge investments in shelter upgradation and it is important to understand why. As per the household interviews in Sanjaynagar, provision of physical infrastructure was reported as most important reason. Better social standing and security of tenure came second and third as reasons for investment. Other reasons stated for investment in housing included marriage in family, dignity of being able to invite relatives to come and stay and the better environment that a new house creates. Similarly, the residents of Khokhra said that they would be interested in investing in housing if they were provided infrastructure facilities and land security. 


\section{CONCLUSIONS}

The conventional development wisdom entails interventions in health, education, income generation and governance as prime leverages of poverty alleviation with safe water and infrastructure sanitation assuming a supportive role. This paper explores the alternative philosophy that water and environmental sanitation can be the principal catalyst of change, alleviating poverty most effectively and at affordable costs. It also assesses the resource potential of the communities and the subsequent investments in improving their housing stock. The main findings are:

- Water and sanitation have a positive impact on health, education, income and housing.

- Communities have highlighted the benefits of individual services in the house interviews and group discussions.

- Communities are willing and can contribute to capital and maintenance costs for infrastructure.

- The 'multiplier effect' of water and sanitation on the ultimate community investment in shelter and goods was found to be 24 times the initial government investment in services.

\section{REFERENCES}

Acharya, S. and Parikh, S.: 2002, Slum networking in Ahmedabad - Poverty and vulnerability in a globalising metropolis. Ahmedabad, Manak Publications, pp 309-348.

Ahmedabad Municipal Corporation (AMC): 2005, Slum Networking - A partnership programme of infrastructure and social development in slums of Ahmedabad city.

Central Statistical Organisation (CSO): 2002, Compendium of environmental statistics India, 2002, chapter 7. Ministry of Statistics \& Programme Implementation, Government of India.

DFID: 2002, Making connections: Infrastructure for poverty reduction. www.dfid.gov.uk/pubs/files

Diacon, D.: 1997, 'Slum Networking -An Innovative Approach to Urban Development', Building and Social Housing Foundation. ISBN 095222786 X.

HC: 2007, Sanitation and Water. Sixth Report of session 2006-07, Vol. 1, Prepared by the International Development Committee, Ordered by the House of Commons (HC), April 2007.

Kolsky, P.: 1998, Storm Drainage: An Engineering Guide to the Low-Cost Evaluation of System Performance. IT Publications.

MCGB (Municipal Corporation of Greater Bombay): 1995, Brief note for World Bank appraisal mission on the Bombay slums and sanitation facilities provided by MCGB.

Parikh, H.: 1995, Slum networking: A community-based sanitation and environmental programme: Experiences of Indore, Baroda and Ahmedabad. Sponsored by Human Settlement Management Institute, New Delhi, India and Institute for Housing and Urban Development Studies, Rotterdam.

Parikh, P.: 2005, 'An Innovative Approach to Physical Infrastructure as a Means to Overcoming Poverty in Developing Countries', MPhil thesis submitted to Cambridge University, Cambridge.

Parikh, P.: 2008, 'Impact of Water and Sanitation Infrastructure on Poverty Alleviation in Low Income Settlements', PhD thesis submitted to Cambridge University, Cambridge. 
Sandhu, R.: 1998, 'Infrastructure development in slums: An experience of a medium size city in Punjab.' in book Slum Upgradation, chapter 10. Bookwell Publications.

SHARDA Trust and SAATH: 1999, 'Sanjay Nagar, A postscript'.

Sneh Prayas: 2004, Household Surveys in Sanjaynagar for Education and Income Levels

Tripathi, D.: 1998, 'Alliance for Change - A Slum Upgrading Experiment in Ahmedabad', Tata McGraw-Hill.

United Nations (UN) (2007) The millennium development goals report 2007. New York

UN-HABITAT (2003) The challenge of slums: Global report on human settlements, 2003. United Nations Human Settlements Program, Earthscan Publishing Ltd.

UNICEF (1999) Urban Initiative - Slum Networking strategy: A community based water and environmental sanitation demonstration project in Ramdevnagar, Baroda. Gandhinagar.

UNICEF/WHO: 2004, 'Meeting the MDG Drinking Water and Sanitation Target, A Mid Term Assessment of Progress'.

UN (n.d.a.) United Nations Millennium Development Goals Indicator.

Available on http://mdgs.un.org/unsd/mdg.

United Nations Development Programme (UNDP) (2006) Human Development Report (HDR): Beyond scarcity: power, poverty and the global water crisis. New York.

World Bank (WB): 2004, 'World Development Report, Making Services Work for Poor People', Oxford University Press, New York. 